\section{THE PROBLEM OF TUBERCULOSIS.}

By H. Hyslop Thomson, M.D.Grasg., D.P.H.LrverP., MEDIOAL OFFICER OF HEALTH FOR THE COUNTY OF HERTFORDSHIRE.

So much has been written about the problem of tuberculosis that any further contribution which contains nothing new with regard to the measures to be adopted for its eradication may well be considered by many as superfluous. The present, however, appears to be an opportune moment to review what has been done in the past and to endeavour to forecast to what extent present efforts require to be supplemented by further practical measures in order that this disease may be adequately and comprehensively dealt with. There exists no royal road to the solution of the problem of tuberculosis, and the present efforts which are being made throughout the country to stem its ravages have suffered to some extent from the fact that they are based on restricted, if expert, views rather than on a broad comprehensive outlook. The question is not infrequently asked why so much energy and thought are directed towards the solution of the tuberculosis problem to the apparent exclusion of other diseases; the answer is that in tuberculosis we have a fairly accurate index of the health standard of a community and that in the absence of any specific cure we are compelled to promote conditions which are inimical to the presence and spread of the disease, with the results that the health standard of the community is raised and resistance to attacks by other forms of disease is increased.

Nomenclature.

Various terms are frequently applied in relation to tuber culosis the use of which should be discouraged. The term phthisis is gradually being discarded, although it is still too frequently used. Pulmonary tuberculosis and lung tuberculosis are the only terms which can correctly be used to designate the pulmonary type of this disease. The popular terms consumption and consumptive, owing to the loose and inaccurate manner in which they are frequently used, are responsible for much of the misconception regarding pulmonary tuberculosis which at present exists in the public mind. While the term consumption is regarded as connoting a disease of high infectivity, the term pulmonary tuberculosis suggests a morbid condition of much less severity. Originally the term consumption was used to designate open cases of lung tuberculosis with classical signs and symptoms, but popularly it has come to be regarded as applicable to all forms of that disease. The confusion caused in a patient's mind when he is informed that he is consumptive bat has not consumption may well be imagined; the former term being sometimes loosely used to designate the so-called pretuberculous stage. It must be admitted, however, that it is extremely difficult to avoid the occasional use of these terms in general practice, although the desirability of educating the public in the correct use of medical terms is obvious. The medical practitioner is frequently asked the question if an individual has consumption and if the condition is one of early quiescent or closed pulmonary tuberculosis. The wisest course to pursue is to answer in the negative, and to state that the condition is one of lung tuberculosis, which if progressive might eventually reach the stage popularly known as consumption. The term pretuberculous has been not infrequently used to indicate a condition of health preceding actual tuberculous infection. As a matter of scientific fact, the majority of so-called pretuberculous cases are cases of early or latent disease, and the term can only be correctly applied to that stage of lowered resistance which precedes actual infection with tubercle bacilli, but as clinically we have no means of recognising or gauging this stage in relation to tuberculosis the term should be discarded, as it is liable to mislead.

\section{Notification.}

The present methods of notification require to be remodelled. More detailed information is necessary so as to amplify and systematise measures adopted to prevent the spread of the disease. The notification form should supply the medical officer of health with definite information regarding the type and stage of the disease, the absence or presence of tubercle bacilli in the sputum, and as to the necessity for precautionary measures or any special form of treatment. A copy of such a notification form should immediately be sent to the medical officer of the authority responsible for the institutional treatment of tuberculosis. Detailed information of this kind supplied at the outset by the general practitioner would facilitate the early and appropriate treatment of the disease and would enable health authorities to map out with ease the districts, streets, and houses in which cases of open tuberculosis most frequently occurred. For such information an increased notification fee would have to be paid, and the grading of such fee according to whether the sputum was examined or not would be desirable; but the value of such pioneer knowledge regarding each individual case is too apparent to require any extended argument. Copies of Notification Form C, giving information of patients' discharged from hospitals and sanatoria, should also be sent to the authority responsible for the scheme of treatment in county districts.

$$
\text { Administration. }
$$

If the present and future schemes for dealing with tuberculosis are to yield sustained and adequate results two essential conditions with regard to administration must be fulfilled. The first is the unification of all effort under one responsible authority, and the second is the provision of adequate facilities for prevention and treatment. Under present administrative arrangements the efficient and expeditious treatment of tuberculosis is impossible. Two authorities are locally responsible for administration in connexion with this disease, and one of these has quite insufficient funds to meet the demands for treatment. This dual responsibility leads to duplication of effort and waste of time in unnecessary clerical work. The treatment of disease is never advantaged by elaborate reports and the expenditure of time and thought on clerical work, hence the desirability of adopting a simpie uniform method of recording cases and of supplying information on application forms for institutional treatment. The sending of patients to various institutions in different parts of the county leads to administrative difficulties, but these cannot be overcome until each authority, or combination of authorities, provides its own facilities for treatment. While existing schemes for dealing with tuberculosis take a fairly comprehensive view of the clinical requirements of the patient they do not include efficient and far-reaching measures for conserving the results of treatment and for preventing ths development and spread of the disease. The care and after-care of tuberculous patients have been left almost entirely to voluntary effort, whereas they should be included as an important supplementary part of official schemes. The questions of housing and occupation in relation to the prevention of the disease and the influence they exercise on the health and economic value of the individual with arrested tuberculosis must also be seriously faced.

\section{Preventive Measures.}

The causes of tuberculosis are too well known to require description. Various conditions tend to impair the resistance of the human body to tuberculosis, and these are intimately associated, and for the most part interdependent. Unhealthy home conditions more than any other factor pave the way for tuberculosis, and they arise from three causes-viz., insanitary surroundings, insanitary houses, and the insanitary habits of occupants. When all three occur the incidence of tuberculosis is high and the health index is low. The abolition of insanitary areas and the provision of adequate and efficient housing accommodation must constitute a part of the campaign against tuberculosis and a serious effort to solve the housing problem when the war is over may be anticipated. Time and effort would be saved by the standardising of certain types of houses for rural districts. Existing houses when they become empty should reach a certain hygienic standard before they are reoccupied. The combined kitchen and sitting-room with a large window surface with efficient cross ventilation and facilities for washing and cleanliness are essential features of a healthy working-class house. The insanitary conditions arising from neglect and ignorance are not so easily combated; in any effort to improve such conditions the services of the medical practitioner might be more extensively utilised. During his professional visits the private medical attendant is in a position to note the evidence of dirt and neglect, the closed window, the diminished cubic space due to overfurnishing, overcrowding, the multitudinous array of knick-knacks which harbour dust, and the food exposed to contamination by dust and flies. By tact and timely suggestion he would be able to secure some improvement; 
but should conditions remain so unsatisfactory as obviously to impair or endanger health he should be in a position to fall back on energetic action by the health authorities. While the modern trend of social improvement is towards the State becoming responsible for much to the individual, the latter must realise that he will be called upon to be responsible for much to the State. Certain channels of infection require to be dealt with by legislative measures if the spread of tuberculosis is finally to be checked and controlled. Legislation to provide a milk-supply free from contamination by tubercle bacilli and other organisms is long overdue, while the provision of central public abbatoirs is an obvious public health measure, in view of the dangers arising from tuberculous meat. The segregation of certain types of laryngeal and pulmonary tuberculosis is also an essential prophylactic measure.

\section{Institutional Treatment.}

The institutional treatment of tuberculosis includes dispensary treatment, sanatorium treatment, the hospital treatment of pulmonary tuberculosis, and the hospital treatment of non-pulmonary tuberculosis. The dispensary provides a centre for the diagnosis and treatment of early cases and for the observation of suspects and doubtful cases. The importance of the dispensary as a unit for the observation and treatment of doubtful cases is obvious when it is realised that by this means a longer term of sanatorium treatment is secured for definite cases of the disease. The insistence of the sanatorium physician for early cases is well known, but the whole scheme suffers if early cases are confounded with doubtful cases. The work in connexion with the dispensary system is for the most part carried out by whole-time officers, and this is, no doubt, the best method of carrying out this part of the scheme, although a closer coöperation between the dispensary officer and the general practitioner is desirable. It has been suggested that the work in connexion with the dispensary should be uniformly carried out by a rota of general practitioners, with the tuberculosis officer acting in a consultative capacity. This would no doubt have certain advantages and would be practicable under altered conditions, but it is difficult to conceive the clerical work inseparable from record-taking recommending itself to the busy practitioner. The hospital treatment of acute and advanced cases of pulmonary tuberculosis constitutes the most important part of the scheme both from the treatment and preventive standpoint. Experience has shown that in the absence of such accommodation a gap exists between the dispensary and the sanatorium which makes efficient and expeditious dealing with tuberculous cases impossible. Hospital treatment means skilled medical attention, efficient nursing, and up-to-date hospital administration, and while it makes provision for the segregation of advanced cases it also provides facilities for the treatment of acute cases of recent onset by induced pneumothorax, antiseptic and other measures, as a result of which a certain proportion are saved. At the present time there exist no compulsory powers for the removal of advanced cases, although such are desirable in certain types of the disease under certain conditions. In the absence of such powers it is necessary to make the hospital inviting to the patient by instituting a reputation for efficiency of treatment and administration. The Hertfordshire County Council has recently opened a hospital with the provision of 30 beds for acute and advanced cases, and the experience of the last few months in that institution has proved that the acme of the infectivity of pulmonary tuberculosis is reached during the last few weeks of life, and that the knowledge of being transferred to the sanatorium when a certain stage of improvement is reached provides a strong incentive to the patient to remain and persevere with treatment.

The sanatorium treatment of tuberculosis has been carried out in this country for over 20 years, and while its benefits are undoubted, its limitations, as the treatment is at present carried out, are definite. That the present sanatorium methods do not yield the results expected must be admitted and the explanation is threefold. Firstly, in the absence of adequate hospital accommodation unsuitable cases are sent to the sanatorium; secondly, the popular view that three months' treatment in a sanatorium will suffice to secure permanent arrest of the disease must be discarded; and, thirdly, the after-care of patients, with the provision of suitable employment, \&c., must constitute an official part of the scheme. If sanatorium treatment is to yield the best results the question of the patient's capacity for work and of his future employment must be intimately linked with the treatment throughout its whole course. The sanatorium should be reserved for early and non-reactive cases, and simultaneously with improvement in health the patient should be instructed and employed in outdoor occupation, experience in which will subsequently prove of value to him. To secure the best results, therefore, the sanatorium should be remodelled on the basis of an industrial institution, while the duration of residence should be considerably increased. In the industrial sanatorium the buildings would be of simple construction, and chief attention would be centred on the land and on facilities for useful employment. No tuberculous patient should be discharged from a sanatorium so long as there exists any possibility of further improvement and while there is no prospect of immediate return to suitable work. Work means wages and food, and good food with healthy home conditions is essential to maintain the condition of arrest and economic care which is obtained by prolonged residence in a sanatorium. The Hertfordshire County Council has purchased a site which is well suited for an industrial sanatorium of this kind, and it is anticipated that on the conclusion of the war the building will be proceeded with. The value of tuberculin in the treatment of pulmonary tuberculosis has been much debated, but, as was pointed out some years ago by the writer, tuberculin gives the best results when employed in the sanatorium at the stage when the beneficial auto-inoculation induced by graduated manual labour is on the wane.

The hospital treatment of non-pulmonary tuberculosis is carried out either in special open-air hospitals or in general hospitals. At the present time the provision of such accom. modation for insured persons is quite inadequate. The treatment of non-pulmonary tuberculosis on rational lines well repays the time and cost involved. Experience has shown that such cases can be efficiently dealt with in general hospitals in small urban districts. The good results obtained by exposing indolent tuberculous lesions to fresh air and sunshine are becoming more fully recognised.

\section{Domioiliary Treatment.}

The question of the domiciliary treatment of tuberculosis is one which calls for some consideration. It must be admitted that domiciliary treatment has not proved as successful as was anticipated. No doubt, owing to the war, it has not had a fair or extended trial, but under the present system it is doubtful if it will prove satisfactory even in normal circumstances. If the domiciliary treatment of tuberculosis is to meet with any measure of success two things must occur at the outset-namely, the existence of fairly healthy home conditions and the recognition of the necessity of rest under open-air conditions when the temperature is raised. In the absence of this essential rest when the temperature is above the normal the individual with pulmonary tuberculosis will sooner or later walk himself into his grave. The present system of domiciliary treatment requires to be remodelled. A uniform method of carrying out the treatment according to well-defined rules is desirable. The method of record-keeping in connexion with domiciliary treatment should be of the simplest character and should consist of a special card similar in some respects to that used in connexion with medical benefit. The present method of payment for the services of the general practitioner in connexion with the treatment of tuberculosis is not quite satisfactory and might with advantage be altered. Some uniform procedure with regard to the prescribing of drugs and appliances is also desirable. A special formulary for use in domiciliary treatment would be a distinct advantage. It would also serve a useful purpose from a prophylactic standpoint if all chemists kept in stock a standardised sputum flask which could readily be obtained by prescription. A closer coöperation between the tuberculosis officer and the family practitioner is desirable. This demands tact and knowledge on the part of the former and willingness to coöperate on the part of the latter. In not a few cases in my own experience the value of such close coöperation to the patient has been proved. Under present conditions, however, the time of the tuberculosis officer is too much occupied in dispensary work to permit of such coöperation, although the importance of a high standard of domiciliary treatment cannot be too strongly emphasised. In domiciliary treatment prevention and treatment must act in unison, as it is in the homes of 
the people that there exists the greatest need for the carrying out of adequate prophylactic measures.

\section{Care Treatment.}

The care treatment of tuberculous patients constitutes an important and essential adjunct to medical treatment. The Pablic Health (Prevention and Treatment of Diseases) Act, 1913, enables public health authorities, with the sanction of the Local Government Board, to carry out measures for the care and control of tuberculous patients. The aim of such measures is to increase and conserve the good results obtained by medical treatment, and at present they are carried out through the agency of voluntary care committees. The experience of the past few years has emphasised the desirability of coördinating such efforts in one comprehensive and official scheme, so that there may be sufficient financial help to secure effective, sustained, and uniform action. The extent to which the working capacity of the individual with arrested tuberculosis is made use of as a national asset depends in large measure on the assistance he obtains in securing suitable employment. The economic question in relation to tuberculosis is of such far-reaching importance that it cannot be overlooked in any comprehensive scheme for dealing with this disease. The outdoor relief granted by boards of guardians to chronic and advanced cases of tuberculosis has frequently proved of value, and it would in great measure solve the problem of care treatment if this department of the Poor-law system so far as it relates to actual disease were reorganised and were transferred to public health authorities as an official system of care and help in connexion with tuberculosis and other diseases.

Tuberoulosis and the War.

One of the many effects of the war has been to broaden our outlook in connexion with tuberculosis and other health problems. The influence exercised by military service on the disease itself is now more accurately estimated. While the conditions inseparable from active service abroad is liable to diminish the resistance to tuberculous infection the life associated with military training in this country undoubtedly exercises a beneficial effect on the health of the soldiers. The military authorities for some time have been exercising considerable care with regard to the admission of possible cases of tuberculosis to the Army. Men with healed or localised latent pulmonary tuberculosis, nowever, are not unfit for certain forms of military or other national service ; indeed, under favourable conditions, they benefit by it. Given fresh air, good food, and regularised physical exercise, such cases undergo marked improvement in general health and physical vigour. The contra-indications, however, are definite, and are as follows : (a) the presence of tubercle bacilli in the sputum, $(b)$ a temperature range above the normal, $(c)$ the presence of crepitations or other gross physical signs, and $(d)$ a history of tendency to hrmoptysis. In the majority of cases discharged from the Army suffering from tuberculosis, in the writer's experience, the men have been on active service and the disease has been acute and progressive in type. This fact accentuates the urgent need for adequate hospital accommodation, for not only is it a national duty to provide the type of treatment best suited to the requirements of each discharged soldier, but it is highly desirable, from the viewpoint of public health, that cases in which the disease is acute or advanced should be transferred immediately to a suitable hospital for treatment.

\section{Conolusions.}

- The death-rate and attack-rate from tuberculosis and the infant mortelity constitute a fairly reliable combined index of the health standard of a community. If these rates are low the death-rate from almost all other diseases is also low, important possible exceptions being malignant disease and organic heart disease. The expenditure incurred in connexion with the treatment of tuberculosis will fail to secure an adequate return unless searching prophylactic measures are simultaneously carried out, and unless such treatment is supplemented by an official scheme to conserve the beneficial economic results obtained. The measures which are recognised as essential for the prevention of tuberculosis are also instrumental in raising the general standard of health and in protecting the individual from other forms of disease; this fact alone emphasises the importance of a broad and comprehensive outlook in dealing with the problem of tuberculosis.
THE CONTROL OF VENEREAL DISEASES.

The American Association for the Control or Syphilis. WE have received from Dr. M. F. Engman, of St. Louis, Mo., a statement of the objects of the American Association for the Control of Syphilis, which was organised at Cincinnati on May 23rd and 24th last. These objects are the promulgation of knowledge of syphilis among medical men, medical institutions, boards of health, hospital boards, dispensary attendants and boards, and other organisations having the care and treatment of syphilis. It is hoped to develop the investigation of the disease from the social and economic sides. Plans are being made to collect standardised statistics from the various institutions now treating syphilis ; to further the establishment of free clinics and dispensaries for the diagnosis and treatment of syphilis; and to encourage the more comprehensive teaching of syphilis in medical schools. The association proposes to operate through a national body and local branches in various cities, acting in close coöperation with the American Social Hygiene Association. The membership of the association at present is composed of the following :-

Dr. W. T. Belfield (Chicago), Dr. Ernest D. Chipman (San Francisco), Dr. W. T. Corlett (Cleveland), Dr. Isadore Dyer (New Orleans), Dr. M. F. Engman (St. Louis), Dr. J. A. Fordyce (New York), Dr. Marcus Haase (Memphis), Dr. H. H. Hazen (Washington), Dr. M. B. Hartzell (Philadelphia), Dr. H. E. Kleinschmidt (St. Louis), Dr. G. M. MacKee (New York), Dr. E. L. McEwen (Chicago), Dr. W. H. Mook (St. Loufs), Dr. H. Morrow (San Francisco), Dr. H. J. Nichols (San Francisco), Dr. Oliver Ormsby (Obicago), Dr. Sigmond Pollitzer (Now York), Dr. W. A. Pusey (Chicago), Dr. A. Ravogli (Cincinnati), Maj. Matthew Reasoner (Washington), Dr. J. F. Schamberg (Philadelphia), Dr. Morton Smith (Boston), Dr. W. F. Snow (New York), Dr. H. W. Stelwagon (Philadelphia), Dr. G. H. Walker (Baltimore), Dr. Grover Wende (Buffalo),
Dr. Udo Wile (Buffalo), Dr. J. M. Winfield (Brooklyn), and Dr. H. R. Varney (Detroit)

The following are the executive officers of the Association : Dr. M. F. Engman, president ; Dr. J. F. Schamberg, vicepresident; Dr. H. E. Kleinschmidt, secretary and treasurer, 607, Federal Reserve Building, St. Louis, Mo.

Unqualified Presoribing and Advertisement.

At the meeting of the London County Council last week the Public Health Committee reported as follows :-

An Order, dated July 18th, has been made by the Local Government Board under section 1 (2) of the Venereal Disease Act, 1917, applying to the areas of certin counties (including London) and county boroughs section 1 (1) of the Act prohibiting any person in such areas other than a qualitied medical practitioner for reward either direct or indirect from treating any person for venereal disease or prescribing any remedy treating any person for venereal disease or prescribing any remedy whether the advice is given to the person to be treated or any other Whether the advice is given to the person to be treated or any other person. The Act also prohibits the issue of advertisements relating to the treatment of venereal disease and, as from Nov. 1st, 1917, the issue of advertisements relating to the sale of preparations to be used as medicines or medicaments for the prevention, cure and relief of any venereal disease. The prohibition with regard to advertisements does not, however, apply to announcements by local or public authorities published with the sanction of the Local Government Board or to publications sent only to duly qualified medical practitioners or wholesale or retail chemists for the purposes of their business.

Treatment of Venereal Disease at Portsmouth.

A report on the work of the department established under the Venereal Disease Act, 1917, was submitted to the Committee of the Royal Portsmouth Hospital at their meeting on July 20th, by Captain A. Cambell, R.A.M.C. (T.), medical officer in charge. A detached building in the grounds of the hospital has been utilised for the purpose. The staff consists of two medical officers, one sister, and two orderlies. The department has been open for five months and during that time there were 152 males, 120 women, and, 26 children, with a daily average attendance of 60 to 70 patients. Civilians only were treated; women patients failed more than men to realise the necessity of attending regularly. Few women living vicious lives sought treatment, but many young girls attended. The attendance of cases of congenital syphilis was most satisfactory, mothers being anxious to bring their children. The results clearly showed that the clinic was doing excellent work.

\section{Facilities in Devon and Cornwall.}

The committee of the Royal Devon and Exeter Hospital has decided, with the sanction of the Local Government Board, to provide an out-patient department for venereal diseases and a certain number of beds for in-patient treatment.

At the last meeting of the Cornwall County Council it was decided to establish at once a clinic for venereal disease in the county at an estimated cost of $£ 400$. 